\title{
Mathematical modelling of electrochemical reactions in aluminium reduction cells
}

\author{
R. N. Kuzmin ${ }^{1}$, O. G. Provorova ${ }^{2}$, N. P. Savenkova ${ }^{1}$ \\ \& A. V. Shobukhov ${ }^{1}$ \\ ${ }^{I}$ Lomonosov Moscow State University, Russia \\ ${ }^{2}$ Siberian Federal University, Russia
}

\begin{abstract}
This paper reports the mathematical modelling of electrochemical processes in the Søderberg aluminium electrolysis cell. We consider anode shape changes, variations of the potential distribution and formation of a gaseous layer under the anode surface. Evolution of the reactant concentrations is described by the system of diffusion-convection equations while the elliptic equation is solved for the Galvani potential. We compare its distribution with the $\mathrm{CO}_{2}$ density and discuss the advantages of the finite volume method and the marker-and-cell approach for mathematical modelling of electrochemical reactions.
\end{abstract}

Keywords: aluminium reduction, electrochemical reaction, gaseous layer, mathematical modelling, finite volume method.

\section{Introduction}

In aluminium reduction cells the carbon anode is placed in the upper part of the bath parallel to the liquid aluminium layer at the bottom, which acts as the cathode. The electrolyte between these electrodes consists of cryolite melt $\mathrm{Na}_{3} \mathrm{AlF}_{6}$ and alumina $\mathrm{Al}_{2} \mathrm{O}_{3}$ dissolved in it; it may also contain such admixtures as $\mathrm{AlF}_{3}, \mathrm{CaF}_{2}$ and others. Dissolving of alumina in the bulk of the cell may be described as follows:

$$
\mathrm{Na}_{3} \mathrm{AlF}_{6}+\mathrm{Al}_{2} \mathrm{O}_{3} \leftrightarrow 3 \mathrm{Na}^{+}+3 \mathrm{AlOF}_{2}^{-} .
$$

Being driven by the electric field, the diffusion and the force of gravity, the ions $\mathrm{AlOF}_{2}-$ reach the electrodes. There they donate and accept the electric charges. The cathode process is:

$$
3 \mathrm{AlOF}_{2}^{-}+6 \mathrm{e}=2 \mathrm{Al}+6 \mathrm{~F}^{-}+\mathrm{AlF}_{4^{-}},
$$


while the anode process looks as:

$$
3 \mathrm{AlOF}_{2}^{-}-6 \mathrm{e}+3 / 2 \mathrm{C}=3 / 2 \mathrm{CO}_{2}+3 \mathrm{Al}^{3+}+6 \mathrm{~F}^{-} \text {, }
$$

where e equals the charge of a single electron. Aluminium is deposited at the cathode; simultaneously the $\mathrm{CO}_{2}$ layer is being formed along the lower horizontal side of the carbon anode, which is consumed in this reaction.

Unlike the conducting liquid metal layer at the bottom, the side walls of the cell are covered with ledge, which is a good insulator. As a result, most of the electric current goes between the cathode and the horizontal part of the anode. It should be emphasised that the conductivity of an electrolyte strongly depends of its composition. In particular, the increase of the $\mathrm{CO}_{2}$ concentration immediately under the anode surface causes an increase of ohmic resistance in this area and leads to the surge of the cell voltage caused by the formation of an insulating layer and to the consequent breakdown of this layer. This phenomenon is known as the anode effect.

Many investigators have carried out mathematical modelling of aluminium electrolysis. In [1-2], for example, the authors dealt mainly with the magnetohydrodynamic (MHD) instability problem and therefore studied the electrolyser behaviour during approximately the first minute after switching on; for this reason they could completely ignore electrochemical reactions. Simulation of the electric field in different parts of the cell and the anode current density distribution was performed using the finite difference, finite elements and the finite volume methods [3-8]. The current distribution in the electrolyte and the variation of the anode shape with time for periods of several days were considered in [4-7]. Never the less, numerical investigation of the simultaneous variations of electrical current and ion concentrations inside the cell have never been performed.

In this paper we combine the approach of [6], which consists in solving the equations for the electric fields in the anode, cathode and the electrolyte under steady state conditions, with our own approximation of the electrochemical reaction and the transport of reactants. We solve a $2 \mathrm{D}$ problem for the Laplace equation coupled with a system of the convection-diffusion equations through use of the boundary conditions. Therefore our problem becomes non-stationary. We study the time period of about one hour and observe the formation of the $\mathrm{CO}_{2}$ boundary layer and the variation of the Galvani potential caused by it.

\section{Theory}

We consider a 2D vertical cross section of an aluminium reduction cell and calculate the electrical field and the concentrations of the reactants in the cell. The temperature is supposed to be constant and equal to $960^{\circ} \mathrm{C}$; the influence of the magnetic field on the electrical field and concentrations is ignored. We also do not simulate the formation of the gas bubbles, but assume that the spreading of $\mathrm{CO}_{2}$ in the sub-anode layer is diffusive.

We denote the Galvani potential of the electrical field as $\varphi$ and the concentrations of AlOF2- and $\mathrm{CO}_{2}$ as $\mathrm{c}_{1}$ and $\mathrm{c}_{2}$ respectively. Initially the anode is rectangular and the concentration of $\mathrm{CO}_{2}$ is zero in the whole cell. According to 
[6], after the voltage is applied to the electrodes, the potential $\varphi_{\mathrm{C}}$ at the cathode surface is given by

$$
\varphi_{C}=-c \cdot j_{C}
$$

where $\mathrm{j}_{\mathrm{C}}$ is the cathode current density and the coefficient $\mathrm{c}=8 \cdot 10^{-2} \mathrm{Ohm} \cdot \mathrm{cm}^{2}$, and the anode surface potential $\varphi_{\mathrm{A}}$ is given by

$$
\varphi_{A}=U-E_{r e v}-a-b \cdot \lg \left(j_{A}\right),
$$

where $\mathrm{j}_{\mathrm{A}}=0.75 \mathrm{~A} \cdot \mathrm{cm}^{-2}$ is the averaged anode current density; $\mathrm{a}=0.50 \mathrm{~V}$ and $\mathrm{b}=0.25 \mathrm{~V}$ decade ${ }^{-1}$ are the Tafel coefficients of the reaction (3) valid for the electrolyte that contains $81 \mathrm{wt} \% \mathrm{Na}_{3} \mathrm{AlF}_{6}, 3 \mathrm{wt} \% \mathrm{Al}_{2} \mathrm{O}_{3}, 11 \mathrm{wt} \% \mathrm{AlF}_{3}, 5 \mathrm{wt} \%$ $\mathrm{CaF}_{2}$ at $960^{\circ} \mathrm{C}$ [6]; $U_{\text {cell }}$ is the cell potential and $\mathrm{E}_{\text {rev }}=1.23 \mathrm{~V}$ is the reversible electrode potential. The distribution of the electrical field in the cell is described by

$$
\operatorname{div}\left(-\sigma\left(c_{2}\right) \cdot \operatorname{grad} \varphi\right)=0 .
$$

where $\sigma\left(c_{2}\right)$ is the electrolyte conductivity. We assume that it depends on the concentration of $\mathrm{CO}_{2}$ in the following way:

$$
\sigma\left(c_{2}\right)=\sigma_{0}+\left(\sigma_{1}-\sigma_{0}\right) \cdot\left(1-\exp \left(-\alpha \cdot c_{2}\right)\right)
$$

Here $\sigma_{0}=2.0 \cdot 10^{0}(\mathrm{Ohm} \cdot \mathrm{cm})^{-1}$ and $\sigma_{1}=1.0 \cdot 10^{-6}(\mathrm{Ohm} \cdot \mathrm{cm})^{-1}$ are the specific conductivities of pure electrolyte and pure $\mathrm{CO}_{2}$ at $960^{\circ} \mathrm{C} ; \alpha=3 \cdot 10^{-1}$ is an empirical parameter. We suppose that the side walls of the cell are electrical insulators as well as the upper electrolyte surface around the anode, because all these surfaces are covered with insulating ledge. This supposition and the eqns (4)-(5) give us the full set of boundary conditions for $\varphi$ :

$$
\begin{aligned}
& \varphi=\varphi_{C} \text { at the cathode surface; } \\
& \varphi=\varphi_{A} \text { at the anode surface; } \\
& \frac{\partial \varphi}{\partial v}=0 \text { at the side walls and at the upper surface. }
\end{aligned}
$$

where $v$ is the normal vector to the boundary. The electrode processes (2) and (3) run in accordance with the Faraday law; therefore the concentrations $c_{1}$ and $c_{2}$ satisfy the following equations at the cathode and anode surfaces:

$$
\begin{gathered}
D_{1} \cdot \frac{\partial c_{1}}{\partial v}=\frac{\left|j_{C}\right|}{n_{C} F} ; \quad \frac{\partial c_{2}}{\partial v}=0 ; \\
D_{1} \cdot \frac{\partial c_{1}}{\partial v}=\frac{\left|j_{A}\right|}{n_{A} F} ; \quad D_{2} \cdot \frac{\partial c_{2}}{\partial v}=\frac{1}{2} \cdot \frac{\left|j_{A}\right|}{n_{A} F} .
\end{gathered}
$$

where $\mathrm{n}_{\mathrm{C}}=3$ and $\mathrm{n}_{\mathrm{A}}=4$ are the numbers of electrons participating in the cathode and anode processes; $\mathrm{D}_{1}=\mathrm{D}_{2} \approx 1.0 \cdot 10^{-5} \mathrm{~cm}^{2} \mathrm{~s}^{-1}$ are the diffusion coefficients [9][10]; $v$ is the normal vector to the electrode surface and F is the Faraday's constant. Inside the cell concentrations satisfy the convection-diffusion equations [11-13]: 


$$
\begin{aligned}
& \frac{\partial c_{1}}{\partial t}=\operatorname{div}\left(D_{1} \cdot \operatorname{grad} c_{1}-m \cdot c_{1} \cdot \operatorname{grad} \varphi\right), \\
& \frac{\partial c_{2}}{\partial t}=\operatorname{div}\left(D_{2} \cdot \operatorname{grad} c_{2}\right),
\end{aligned}
$$

where $\mathrm{m}=-1$ is the electric charge of the $\mathrm{AlOF}_{2^{-}}$ion measured in the electron charge units. The reactants do not permeate through the side walls of the cell; therefore the boundary conditions for $\mathrm{c}_{1}$ and $\mathrm{c}_{2}$ at them look as follows:

$$
\frac{\partial c_{1}}{\partial v}=\frac{\partial c_{2}}{\partial v}=0
$$

where $v$ is the normal vector to the walls. Finally we should take into account the changes of the electrodes [6] during the electrochemical reaction. From Faraday's law it follows that the rate of the cathode vertical shift is

$$
u_{C}=\frac{M_{1}}{n_{C} F \rho_{1}} \cdot\left|j_{C}\right|,
$$

where $M_{1}$ and $\rho_{1}$ are the molar mass and the density of aluminium, while the rate of the anode shift in the direction orthogonal to its surface is

$$
u_{A}=\frac{M_{2}}{n_{A} F \rho_{2}} \cdot\left|j_{A}\right|,
$$

where $\mathrm{M}_{2}$ and $\rho_{2}$ are the molar mass and the density of carbon. It should be mentioned that the cathode surface remains horizontal, because it is the surface of the liquid aluminium pool and the normal vector to it remains vertical, while the anode surface changes its shape, and the direction of its normal vector varies. We study rather small periods of time, around one hour, so the anode consumption is practically negligible, though we take it into account as well. Yet, unlike [4-7], we do not look for the steady state anode shape.

\section{Finite volume approximation}

We use the finite volume method for numerical approximation of the eqns (4)(14). The whole area is treated as a set of rectangular blocks - see Fig.1

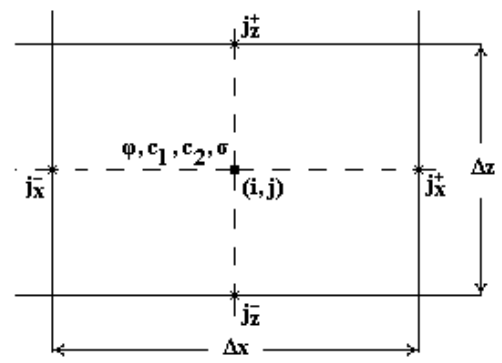

Figure 1: Block of the grid. 
The blocks, or elementary volumes, form the grid. The blocks are numbered with two indexes, $i$ and $j$, in the horizontal and vertical direction respectively. The horizontal axes is denoted as $\mathrm{x}$ and the vertical one - as $\mathrm{z}$. The sizes of the block along these axes are denoted as $\Delta x$ and $\Delta z$. The values of $\varphi, c_{1}, c_{2}$ and $\sigma$ are located in the centre of the block and are supposed to be constant in it. The current density vector $\mathbf{j}$ has the horizontal and vertical components: $\mathbf{j}=\left(\mathrm{j}_{\mathrm{x}}, \mathrm{j}_{\mathrm{z}}\right)$; these components are assigned to the centres of the block sides; see Fig.1. Ohm's law in vector notation gives us the relation between $\varphi$ and $\mathbf{j}$ :

$$
j_{x}=-\sigma \frac{\partial \varphi}{\partial x} ; \quad j_{z}=-\sigma \frac{\partial \varphi}{\partial z} .
$$

The eqns (15) are approximated on the grid in the following way:

$$
\begin{aligned}
& j_{x}^{+}=-\frac{\sigma_{i+1, j}+\sigma_{i, j}}{2} \cdot \frac{\varphi_{i+1, j}-\varphi_{i, j}}{\Delta x} ; \\
& j_{z}^{+}=-\frac{\sigma_{i, j+1}+\sigma_{i, j}}{2} \cdot \frac{\varphi_{i, j+1}-\varphi_{i, j}}{\Delta z} .
\end{aligned}
$$

Similar approximations are done for $\mathrm{j}_{\mathrm{x}}-$ and $\mathrm{j}_{\mathrm{z}}$. The eqn (6) may be rewritten as an integral of the current density normal to the block boundary:

$$
\oint_{\mathbf{S}}(j, v) d S=0,
$$

where $\mathrm{S}$ is the boundary of the block and $\mathbf{v}$ is its normal vector, and therefore is approximated as

$$
\left(j_{x}^{+}-j_{x}^{-}\right) \cdot \Delta z+\left(j_{z}^{+}-j_{z}^{-}\right) \cdot \Delta x=0 .
$$

The eqns (11)-(12) are treated in the same manner: given the concentration $\mathrm{c}$ (where $\mathrm{c}$ stands for $\mathrm{c}_{1}$ or $\mathrm{c}_{2}$ ) in the centre of the block, we approximate the concentration gradient $\mathbf{h}=(\partial \mathrm{c} / \partial \mathrm{x}, \partial \mathrm{c} / \partial \mathbf{z})$ at the centres of the block sides:

$$
h_{x}^{+}=\frac{c_{i+1, j}-c_{i, j}}{\Delta x} ; h_{z}^{+}=\frac{c_{i, j+1}-c_{i, j}}{\Delta z} .
$$

Again similar approximations are done for $\mathrm{h}_{\mathrm{x}}-$ and $\mathrm{h}_{\mathrm{z}}$ - Then the divergences in eqns (11-12) are treated as the integrals of the normal components of their arguments over the block boundary as it was done with the eqns (18-19). Finally for approximation of the time derivatives in the left-hand side of the eqns (11-12) we apply the symmetrical difference scheme. We replace the time derivatives with appropriate finite differences:

$$
\frac{\partial c}{\partial t} \approx \frac{c_{i, j}(t+\Delta t)-c_{i, j}(t)}{\Delta t}
$$

and equate them to half-sums of the right hand side approximations on the next and current time layers. The obtained system of algebraic equations is solved together with (18) using Seidel's iterative method. This scheme approximates the original equations with the second order of accuracy with respect to $\mathrm{t}, \mathrm{x}, \mathrm{z}$ and is 
unconditionally stable [14]. Besides it guarantees the conservation of current and matter: no artificial sources or drains of electric charges and reagents may appear during computation $[6,14]$.

All elementary volumes are divided into three types: A (anode), B (electrolyte) and C (cathode) blocks (see Fig.2). Eqns (18-19) may be written only for blocks $\mathrm{B}$, because the electrodes (that is, blocks $\mathrm{A}$ and $\mathrm{C}$ ) are equipotential and contain only carbon and aluminium, while blocks $\mathrm{B}$ contain a mixture of ions and molecules, $\mathrm{AlOF}_{2}$ - and $\mathrm{CO}_{2}$ in particular.

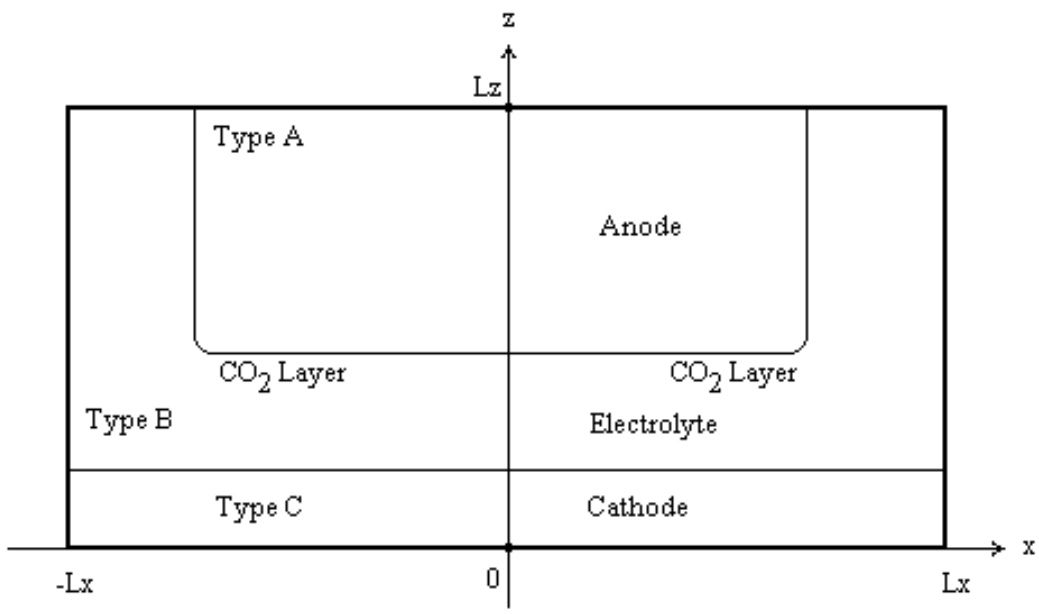

Figure 2: $\quad$ Scheme of the electrolyser.

Those blocks of types A and C that are situated at the electrolyte-electrode border are used for approximating the boundary conditions given by eqns (8) and (16). The electrode surfaces are determined in the following way [15]: we introduce special markers (imaginary particles) that are originally placed in the centres of those blocks of type B that are adjacent to the blocks of types A and C. The coordinates of these markers are found from eqns (14) and (15) so they delimitate the border. As soon as any of these particles leaves the B-type block and enters the A-type or C-type one, the type of the entered block is changed to B. If the particle leaves the B-type block for another B-type one (as it happens at the cathode surface), the empty block is assigned the type of the adjacent non-Btype block (in the considered problem it's always $\mathrm{C}$ ).

\section{Results and discussion}

We considered the aluminium reduction cell section one meter wide and halfmeter high $\left(\mathrm{L}_{\mathrm{x}}=\mathrm{L}_{\mathrm{z}}=50 \mathrm{~cm}\right.$ at Fig.2). Initially the depth of the cathode aluminium pool is $5 \mathrm{~cm}$; horizontal and vertical sizes of the carbon anode are $70 \mathrm{~cm}$ and $30 \mathrm{~cm}$ respectively; the gap between the anode and the side walls and the distance between the electrodes equals $15 \mathrm{~cm}$. We use the rectangular grid containing 100 
blocks vertically and 200 blocks horizontally; it gives us $\Delta \mathrm{x}=\Delta \mathrm{z}=5 \cdot 10^{-1} \mathrm{~cm}$. The step $\Delta \mathrm{t}$ is taken equal to 1 second and $10^{4}$ time layers are computed in a single series, which gives us nearly 3 hours of the physical time. In Figure 3 we demonstrate the equipotential lines of $\varphi$ with the step $0.4 \mathrm{~V}$ for $\mathrm{t}=1 \mathrm{sec}$. The distances between these lines are practically equal. It proves that the conductivity of electrolyte at this moment doesn't vary in the whole volume of the cell. The boundary conditions for $\varphi$ are given by eqn (8); it imposes $\partial \varphi / \partial v=0$ along the walls and the upper anode boundary.

However, the distribution of the potential is different for $t=1$ hour. The same equipotential lines for $t=1$ hour are shown in Fig.4. It is easy to see that now the greatest voltage drop occurs in a narrow region directly below the anode.

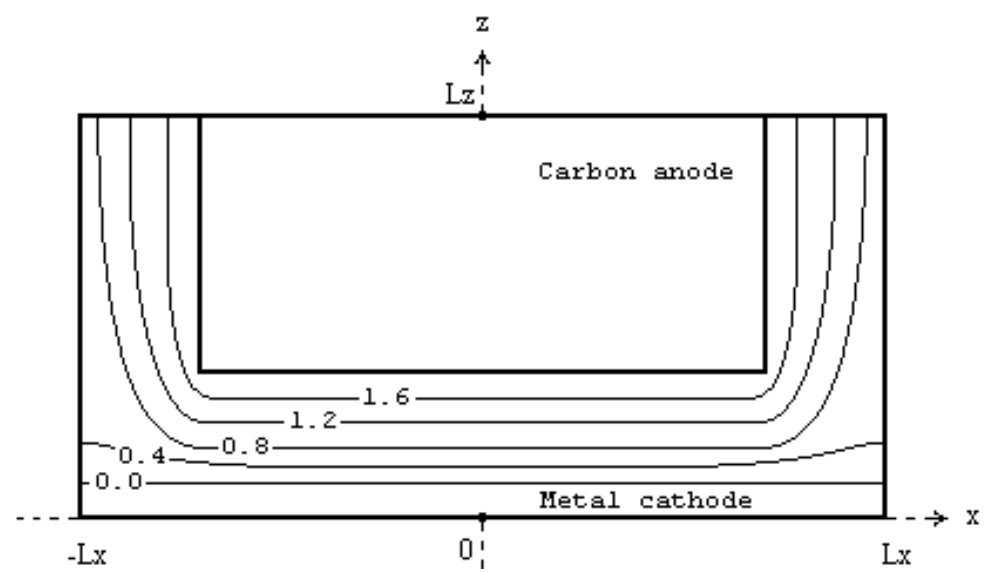

Figure 3: Equipotential lines in the electrolyte (units in $\mathrm{V}$ ) for $\mathrm{t}=1 \mathrm{sec}$.

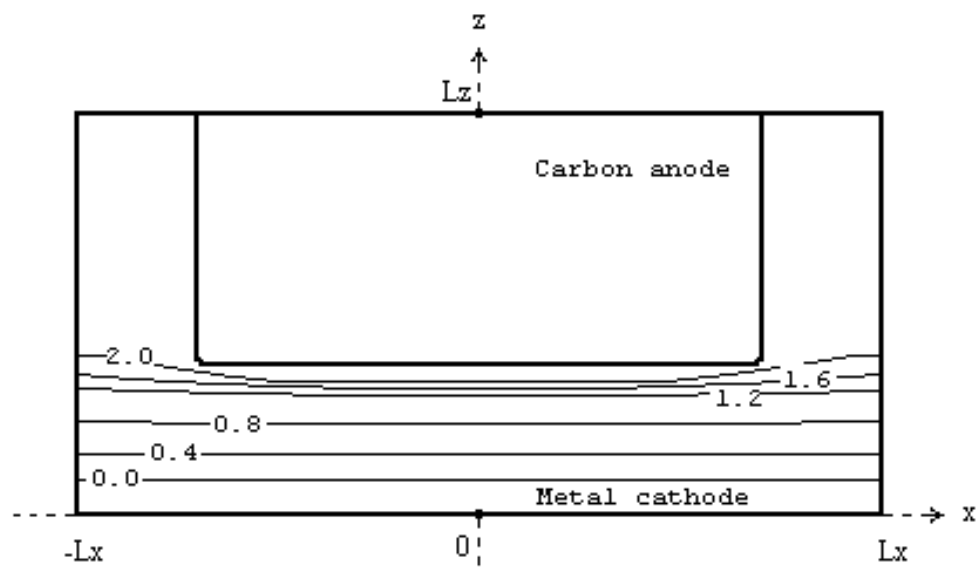

Figure 4: Equipotential lines in the electrolyte (units in $V$ ) for $\mathrm{t}=1$ hour. 


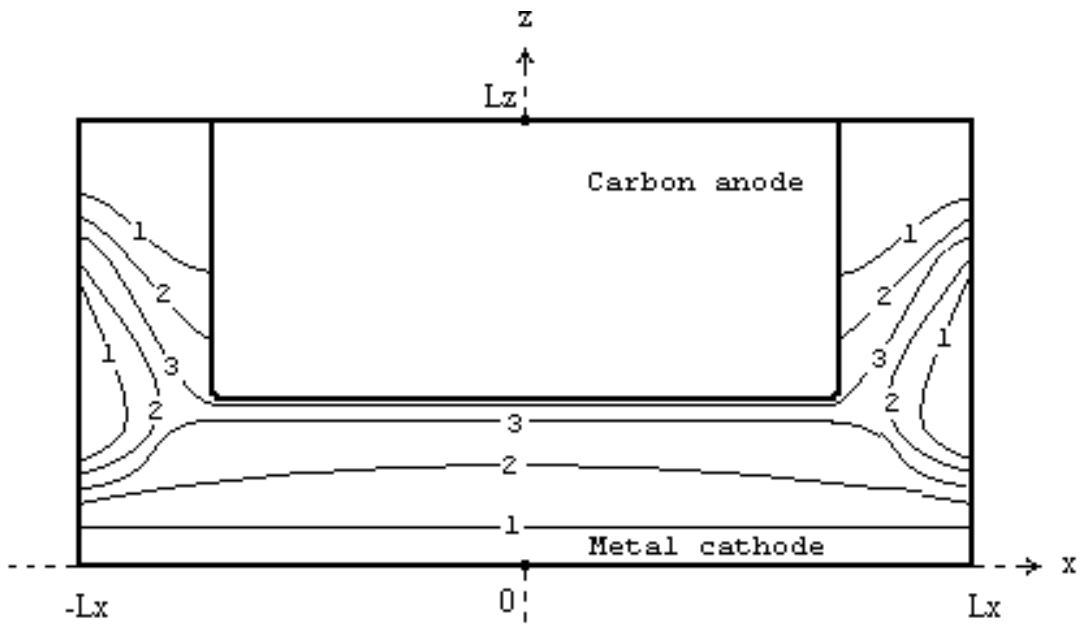

Figure 5: Contours of the $\mathrm{CO}_{2}$ concentration for $\mathrm{t}=1$ hour. The levels: $1-$ $1 \cdot 10^{-6} \mathrm{~mol} / \mathrm{cm}^{3}, 2-1 \cdot 10^{-5} \mathrm{~mol} / \mathrm{cm}^{3}, 3-5 \cdot 10^{-5} \mathrm{~mol} / \mathrm{cm}^{3}$.

The anode potential also starts growing. These results are easily explained by considering the concentration of $\mathrm{CO}_{2}$ in the bath. Initially there is no $\mathrm{CO}_{2}$ in the cell. It appears as a result of the anode process (3) and forms a layer with low specific conductivity, as it is shown in Fig.5.

Comparing Fig. 4 and 5, we see that the voltage drop region coincides with the zone of high $\mathrm{CO}_{2}$ concentration. The change of the anode shape is rather small and may be observed mainly in the corners of the electrode. It agrees with previous experimental and numerical results [6-8]; it takes 6 to 8 days to reach the constant anode shape. Never the less, the amount of carbon, consumed during the first hour, is enough to form a layer of $\mathrm{CO}_{2}$, sufficient for transform the electric current distribution inside the cell.

\section{Conclusions}

It follows from the above discussion and numerical results that even a simple convective-diffusive model of concentration behaviour mechanism gives realistic results and yields a satisfactory description of the formation of the gaseous layer under the anode surface. The model may be improved by adding the electrolyte circulation and electromagnetic forces; yet we hope that it will not change the main conclusions. The finite volume method proves to be a flexible and sufficiently accurate numerical technique for solving both the equations for the Galvani potential and the reactant concentrations. The marker-and-cell approach makes it possible to outline the electrode surfaces easily. 


\section{References}

[1] Munger, D., Vincent, A., A level set approach to simulate magneto hydrodynamic instabilities in aluminium reduction cells. Journal of Computational Physics, 217, pp. 295-311, 2006.

[2] Safa, Y., Flueck, M., Rappaz, J., Numerical simulation of thermal problems coupled with magneto hydrodynamic effects in aluminium cell. Applied Mathematical Modelling, 33, pp. 1479-1492, 2009.

[3] Piotrowski, A., Pietrzyk, S., Metall. \& Foundry Eng., 16, pp.315-337, 1990.

[4] Kuang Z., Thonstad, J., Current distribution in aluminium electrolysis cells with Søderberg anodes. Part I: Experimental study and estimate of anode consumption. Journal of Applied Electrochemistry, 26, pp. 481-486, 1996.

[5] Zoric, J., Roušar, I., Kuang Z., Thonstad, J., Current distribution in aluminium electrolysis cells with Søderberg anodes. Part II: Mathematical modelling. Journal of Applied Electrochemistry, 26, pp. 795-802, 1996.

[6] Zoric, J., Roušar, I., Thonstad, J., Mathematical modelling of industrial aluminium cells with prebaked anodes. Part I: Current distribution and anode shape. Journal of Applied Electrochemistry, 27, pp. 916-927, 1997.

[7] Zoric, J., Roušar, I., Thonstad, J., Mathematical modelling of industrial aluminium cells with prebaked anodes. Part II: Current distribution and influence of sideledge. Journal of Applied Electrochemistry, 27, pp. 928-938, 1997.

[8] Provorova O.G., Kuzmin R.N., Savenkova N.P., Shobukhov A.V., Mathematical modelling of aluminium electrolysis. Proc. of the $9^{\text {th }}$ Int. Conf. on Boundary Value Problems and Mathematical Modelling, Novokuznetsk, 1, pp.103-106, 2008.

[9] Sterten, Á., Solli, P.A., Cathodic process and cyclic redox reactions in aluminium electrolysis cells. Journal of Applied Electrochemistry, 25, pp. 809816, 1995.

[10] Sterten, Á., Solli, P.A., An electrochemical current efficiency model for aluminium electrolysis cells. Journal of Applied Electrochemistry, 26, pp. 187-193, 1996.

[11] Powell, A.C., Shibuta, Y., Guuer, J., Becker, C.A., Modelling Electrochemistry in Metallurgical Processes. The Journal of the Minerals, Metals \& Materials Society, 59(4), pp. 50-58, 2007.

[12] Grafov, B.M., Martemjanov, S.A., Nekrasov, L.N., The Turbulent Diffusion Layer in Electrochemical Systems, Nauka: Moscow, pp. 6-22, 1990.

[13] Damaskin, B.B., Petrii, O.A., Tsirlina, G.A., Electrochemistry, Khimiya: Moscow, pp. 417-422, 2006.

[14] Samarskii, A.A., Goolin A.V., Numerical Methods in Mathematical Physics, Nauchnii Mir: Moscow, pp.271-274, 2000.

[15] Harlow, F.H., Welch, J.E., Numerical Calculation of Time-Dependent Viscous Incompressible Flow of Fluid with Free Surface. Physics of Fluids, 8, pp.2182-2189, 1965. 